Asian Journal of Marketing Management (AJMM)

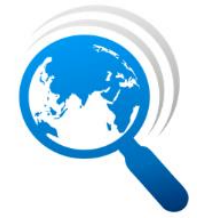

2022, Vol (0I), Issue (0I), 67-88

Copyright $\odot$ University of Sri Jayewardenepura

ISSN: 2820-203I (Printed)

ISSN: 2820-2082 (Online)

DOI: https://doi.org//0.3/357/ajmm.vli01.5468

Reprints and Permission: ajmm@sjp.ac.lk

\title{
Factors influence the choice of Word-of-Mouth recommendation sources in online purchase decisions: with special reference to the tourism and hospitality industry in Sri Lanka
}

\author{
T. M. Eratne \\ University of Sri Jayewardenepura, Sri Lanka \\ M. A. A. Malkanthie \\ University of Sri Jayewardenepura, Sri Lanka
}

\begin{abstract}
Purpose: Word-of-Mouth is a strong communication tool which is perceived as a credible source by consumers. With the internet penetration now WOM is occurring in e-platforms such as blogs, social network sites etc. This has given birth to electronic Word-of-Mouth or e-WOM. Though WOM may occur from various recommendation sources based on various factors the choice of the WOM recommendation source may vary. The research focuses on three objectives. They are to identify the relationship between the perceived task difficulty and the tie-strength of the recommendation source when making an online purchase decision, to identify the relationship between consumer knowledge and perceived task difficulty and to identify the relationship between internet experience and perceived task difficulty.
\end{abstract}

Design/methodology/approach: Data was collected through a questionnaire. A sample of 140 respondents was used to collect information and convenience sampling method was used.

Findings: Results revealed that consumers tend to reach out to both strong ties and weak ties irrespective of the perceived task difficulty. Further as consumer subjective knowledge and internet experience increases perceived task difficulty reduces.

Originality: Although studies have been conducted regarding WOM, no studies have been conducted to understand the role of recommendation sources when making an online purchase decision in the hospitality and tourism industry in the Sri Lankan context.

Implications: Thus word -of -mouth communication should be considered as a part of the communication mix and organizations in the tourism and hospitality industry should focus on using opinion leaders to promote products.

Keywords: WOM, eWOM, Perceived Task Difficulty, Internet Experience, Recommendation Sources

Corresponding Author: T.M. Eratne, Department of Marketing Management, Faculty of Management Studies and Commerce, University of Sri Jayewardenepura, Sri Lanka, Email: thari.eratne@gmail.com 


\section{INTRODUCTION}

Growth of internet has changed the retail landscape. It has provided the opportunity for consumers to make purchases not only from physical stores but also from online stores. Internet and ecommerce have become the most convenient mode of shopping for shoppers around the globe. This is fueled by the expansion of types and features of devices (such as smartphones) that could be used to purchase goods and services online and to search for information related to products and services easily. (Grewal, et al., 2017, Maity, et al., 2018).

Along with the increase of the use of internet, the number of platforms that is available to consumers to share their opinions has expanded (eg: social media, blogs). Consumers are actively making use of these platforms to review products and services, share their product experience and to search for information about products they intend to buy or services they are expecting to experience These platforms are significantly changing everyday life and the affiliation between customers and product and service providers (Huete-Alcocer, A Literature Review of Word of Mouth and Electronic Word of Mouth: Implications for Consumer Behavior, 2017).

Word-of-mouth communication is among the oldest methods of information sharing. (Dellarocas, 2003). Along with rise of internet usage, word of mouth has taken an electronic form giving birth to a new era of word-of mouth which is known as electronic word of mouth (eWOM). Hence eWOM can be considered as a sub section under WOM.

According to research done by Neilsen, consumers tend to trust earned media over owned media. $83 \%$ trust comments and recommendations shared by people they know, $66 \%$ of respondents believe and have faith on opinions shared by other consumers online regarding products and services. Both these fall under word-ofmouth communication. When it comes to taking action, majority of respondents take action based on opinions posted online by people they know or unknown to them. When looking at regional results, $85 \%$ of respondents in the Asia Pacific region trust recommendations from people they know and that is considered the most trusted source. These statistics show the significant role of word-of-mouth communication for marketers. Hence it is worth exploring the role of word-of-mouth promotions and the role of different recommendation sources in the Sri Lankan context related to the hospitality industry.

Prior to the COVID-19 pandemic hitting the country, the tourism industry was among the top three industries that earned foreign exchange in Sri Lanka. Being an island destination, the country has attractive beaches as well as misty mountains that attract tourists from across the globe. Due to favorable weather conditions, travelers visit the country throughout the year. In 2019, the country recorded over 1.9 million 
tourist arrivals and earned USD 3.5 billion income through tourism and related industries. Even though there is a decline in revenue generated from the industry and tourist arrivals due to the pandemic and travel restrictions, even in a post-pandemic economy, tourism plays a major role in rebuilding the Sri Lankan economy ( International Trade Administration, 2021). Further, as online purchases increase organizations in hospitality and tourism can use their websites to increase sales rather than using traditional methods. From an organizational point of view this supports in reducing operational costs of the company. From the customer point of view consumers tend to use online platforms to collect rich and comprehensive information when making travel plans (Huang, Goo, Nam, \& Yoo, 2017). Therefore, the research will focus on understanding the role of word-of-mouth communication and recommendation sources of the tourism and hospitality industry.

When making purchase decisions consumers tend to seek recommendations from different sources - close sources and weak sources. When it comes to family or close friends that a person interacts with frequently, it is considered that a strong relationship exists due to personal knowledge shared. Hence such sources are considered as strong tie recommendation sources. In contrast, weak tie recommendation sources are acquaintances or strangers who provide information on a specific matter or product/ service. Since there is no personal interaction, such sources are considered as weak tie recommendation sources (Hu, Wang, Jiang, \& Yang, 2019).

Although many studies have been done targeting WOM (Seo, et al., 2020; Duhan, et al., 1997; Park, et al., 2021; Tran \& Strutton, 2020; Chun \& Lee, 2016) little attention has been paid on studying about the influence of WOM recommendation sources and tie strength when making an online purchase decision. Several research has been done related to WOM in the Sri Lankan context (Muniweera, et al., 2020; Ashan \& Fernando, 2021; Jesuthasan, et al., 2020). However, this research doesn't capture the role of the recommendation source (online and offline) in word-ofmouth communication. In order to bridge that gap, this research was conducted.

Hence the research problem can be stated as, what are the factors influencing the choice of word-of-mouth recommendation sources when making an online purchase decision. The research will be looking at understanding the role of WOM recommendation sources which include online and offline sources.

\section{LITERATURE REVIEW}

\section{Word of Mouth Communication}

Word of mouth communication is the communication between two parties shoppers or users of products or services, regarding their experience. As this is an information-sharing process about the personal experience it is considered independent and free of commercial intention. (Litvin, Goldsmith, \& Pan, 2008). 
This mode of communication is considered to be more powerful as the company or the seller of products is not involved in the process and has no influence on the comments and reviews shared by the user. As it is free of commercial influence word of mouth is considered more trustworthy and powerful (Brown, Broderick, \& Lee, 2007).

Most of the definitions say that WOM is an informal, interpersonal mode of communication between parties. All the above-mentioned authors focus on the informal aspect of WOM communication. According to Silverman (2001), WOM communication can occur face-to-face, by phone, e-mail, mailing list or any other form of communication (e.g: internet platforms) (Silverman, 2001).

Due to the intangible aspect of services and experience, word of mouth communication is considered more important and powerful when it comes to services and experiences. Due to the intangible nature as the experience cannot be evaluated prior to consumption, reviews and prior experience of others play a major role in consumer decision-making process related to services and experiences. (Huete-Alcocer, 2017).

\section{eWOM}

Any optimistic or harmful and damaging information shared by a current, former or potential user or purchaser of a product or service, regarding the given product or service through an electronic platform such as the internet can be defined as electronic word of mouth or eWOM. As this is shared via electronic platforms that are accessible by many, the information is available to a larger audience (Hennig-Thurau, Gwinner, Walsh, \& Gremler, 2004). eWOM can be considered as a branch under WOM communication. eWOM can be created by both consumers and merchants. According to previous research findings, $61 \%$ go through websites for product information prior to make a purchase decision; meaning they consider eWoM during the decision-making process and $80 \%$ of consumers only purchase products after going through reviews shared by previous users (Yusuf, Hussin, \& Busalim, 2018). The extensive growth in online social networks such as social media, blogs and vlogs has immensely expanded the potential impact of eWOM on consumer purchasing decisions. The eWOM has found a new way to declare its value to product marketing in new forms of communication, such as weblogs, discussion forums, social network websites or review websites (Duartea, Silva, \& Ferreira, 2018).

Increasing use of social media networks provide a great platform for the occurrence of eWOM (Chu \& Choi, 2011). When reviewing past literature, it shows evidence that eWOM is an important means of consumer expression of product-related information and ideas. When it comes to brand management, companies can start viral marketing and eWOM marketing campaigns due to the effectiveness. But once the campaign is released it becomes uncontrollable (Ennew, Banerjee, \& Li, 2000). 
Therefore, this has a critical and very high impact on brand image and brand awareness of a product/brand (Zhang, Jansen, Sobel, \& Chowdury, 2009).

\section{Recommendation Sources and Tie-Strength}

As shared previously, it is common for consumers to consider opinions and views of others when making a purchase decision. Rise of internet and growth of technology have provided quick and easy access to consumers to eWOM across the globe shared by different people. Through social networking sites available, consumers tend to seek information and messages from people with whom they have strong relationships as well as weak relationships.(Choi, Seo, \& Yoon, 2017). According to Granovetter (1973) a blend of the amount of time spent, the level of emotional involvement and concentration, the degree of closeness and understanding between parties can be defined as tie-strength. With members of society that a person interacts mostly with and shares common interests with, they tend to share close relationships; hence such sources such as family and friends are considered as strong ties. In contrast to that, acquaintances or strangers who don't interact closely with a person are considered as weak ties (Granovetter, 1973).

An eWOM message can be shared by people who have strong ties with the consumer (e.g., families, close friends), or by people who have weak ties with the consumer (e.g., acquaintances). Due to great similarity and personal knowledge, consumers tend to rely on strong ties as the preferred source of recommendation source when making decisions (flow of influence) while weak tie eWOM can expose consumers to a broader spectrum of product information and experience (flow of information) (Wang, Wang, \& Wang, 2018).

Besides having relational strength, however, strong ties tend to own both an informative and a structural weakness. Due to similar background and interests among strong ties, the information shared by them tends to be redundant; this is referred to as the informative weakness. The structural weakness lies in transitive closure. To explain it further through an example, in a friends' circle, one person's friends are also friends of others. As it is a closed group, information doesn't spread to outside parties that exist outside of this circle and vice versa. In contrast, weak ties exist between individuals who do not have much in common, including other contacts and the information access.

Weak ties tend to provide excessive information but shares information through a wide network (Hu, Wang, Jiang, \& Yang, 2019). However, due to networks that exist outside close ties, there can be situations that strong ties share non-redundant information. When word of mouth referral is heard from several sources the ability to link it with a close tie increases the chance of making a purchase decision $(\mathrm{Hu}$, Wang, Jiang, \& Yang, 2019). 


\section{Relationship between Perceived Task Difficulty and Recommendation Source Type}

Perceived task difficulty can be defined as an individual's perception of the difficulty of the complexity of the task (Li, Lee, \& Solmon, 2007). It can be considered as a subjective judgement on the complexity of a task (Nawaz, et al., 2021). Perceived Task Difficulty can be further defined as the extent to which the work related to the task can be analyzed and how familiar a person is with the steps that should be followed to performing the task (Van de Ven, Delbecq., 1974).

The difficulty level of a consumer's decision task environment can be evaluated based on the number of product substitutes available to make the choice and the number of product features or product attributes considered when making the choice. This resembles the information available to the decision-maker and the amount of information he/ she should consider when making the purchase decision. (Duhan, Johnson, Wilcox, \& Harrell, 1997). A small number of options or a small number of attributes makes a task easier because the information load is lesser (and vice versa) (Duhan, Johnson, Wilcox, \& Harrell, 1997).

Tasks that are perceived as risky and difficult based on the risk level and the perceived difficulty of the task, and the information sources the decision-maker seeks vary (Locander and Herman, 1979). As the level of perceived task difficulty increases, the level of self-confidence about making the right product decision decreases. Therefore decision-makers tend to reach out to other people who are similar to them and have more confidence in, to get more information regarding the decision and to ensure that they are making the right decision (Brown and Reingen, 1987). Therefore, as perceived task difficulty increases the probability to search for information from strong-tie sources increases (Duhan, Johnson, Wilcox, \& Harrell, 1997).

H1: There is a significant relationship between the perceived task difficulty and strong tie recommendation sources

$\mathrm{H} 2$ : There is a significant relationship between perceived task difficulty and weak tie recommendation sources

\section{Consumer Knowledge}

Prior knowledge can be defined as the degree of involvement and awareness of a product, meaning it is about the level of information that can be recalled from memory regarding a product prior to searching for information from external sources. As the previous knowledge of a product increases the mental schema related to the product tends to be more developed. Further as the previous 
knowledge related to a product increases the ability to process new information also increases (Duhan, Johnson, Wilcox, \& Harrell, 1997).

Knowledge can be divided into two sections as "subjective" and "objective". Subjective knowledge relates to what individuals perceive that they know regarding a given subject while objective knowledge is what individuals actually know in a given context (Mattila \& Wirtz, 2002). As a measure subjective knowledge may lead to individual biases as the consumer may not follow an objective process when comparing himself/herself to others or he/she might be under- or over-confident of their actual knowledge level. Although it is subject to uncontrollable factors, it is a valuable measure because perception of one's knowledge affects the choices of information sources (Duhan, Johnson, Wilcox, \& Harrell, 1997).

\section{Relationship between Consumer Knowledge and Perceived Task difficulty}

Consumers who have high levels of prior knowledge do not process all information they come across. Along with the previous knowledge they have they tend to filter the information and therefore much faster in evaluating alternatives and making decisions, in contrast when consumers have limited prior knowledge, they tend to spend time searching for more information, which delays the decisionmaking process. A higher level of prior knowledge supports the information retrieval process and decoding the brand message which supports the decisionmaker's judgment and brand evaluation, while consumers with less levels of prior knowledge depicts the opposite behavior (Naderi, K.Paswan, \& Guzman, 2018). Higher the prior knowledge consumers have a better cognitive framework which facilitates them in their information search process. Low levels of prior knowledge account for an increase in perceived decision task difficulty (Duhan, Johnson, Wilcox, \& Harrell, 1997). Hence it can be said that when consumers have a higher knowledge on a given matter their perceived task difficulty reduces and thereby, they tend to make decisions faster.

H3: There is a significant relationship between objective prior knowledge and perceived level of task difficulty

H4: There is a significant relationship between subjective prior knowledge and perceived level of task difficulty 


\section{Relationship between Internet Experience and Perceived Task Difficulty}

Experience leads to behavior. Previous experience triggers memories which help to access previous knowledge, and this will help in the process of shaping consumer intentions. Therefore, it can be said that experience has an impact on shaping people's attitudes towards new incidents and situations (Su, Wang, \& Yan, 2018).

It was claimed that previous experience in using internet would drastically reduce the mental effort and the time spent on learning and steering the online shopping process. Therefore, as the previous internet experience increases, online purchases too are likely to increase (Naseri \& Elliot, 2011). Research further says that experience with the internet would reduce the time spent on navigating the website to search for information and thereby increase the likelihood of online purchase. Therefore, prior experience on the internet is likely to reduce the perceived task difficulty of making an online purchase decision.

Users with higher levels of internet experience have the skills and confidence to use the internet for a wide range of activities (Wang \& Law, 2020). Naseri and Elliot (2011) have mentioned that perceived risk reduces with experience. New internet users, due to lack of experience and knowledge gained through experience are less comfortable using the internet. Therefore, they are less satisfied with their internet skills and are more likely to encounter higher stress levels and problems. Hence, lack of internet experience may increase the level of perceived task difficulty regarding online purchases. Therefore, it can be argued that fresh internet users may find it difficult to make decisions regarding online purchases. Therefore, it can be said that consumers with prior internet experience have a low level of perceived task difficulty.

H5: There is a significant relationship between internet experience and perceived level of task difficulty.

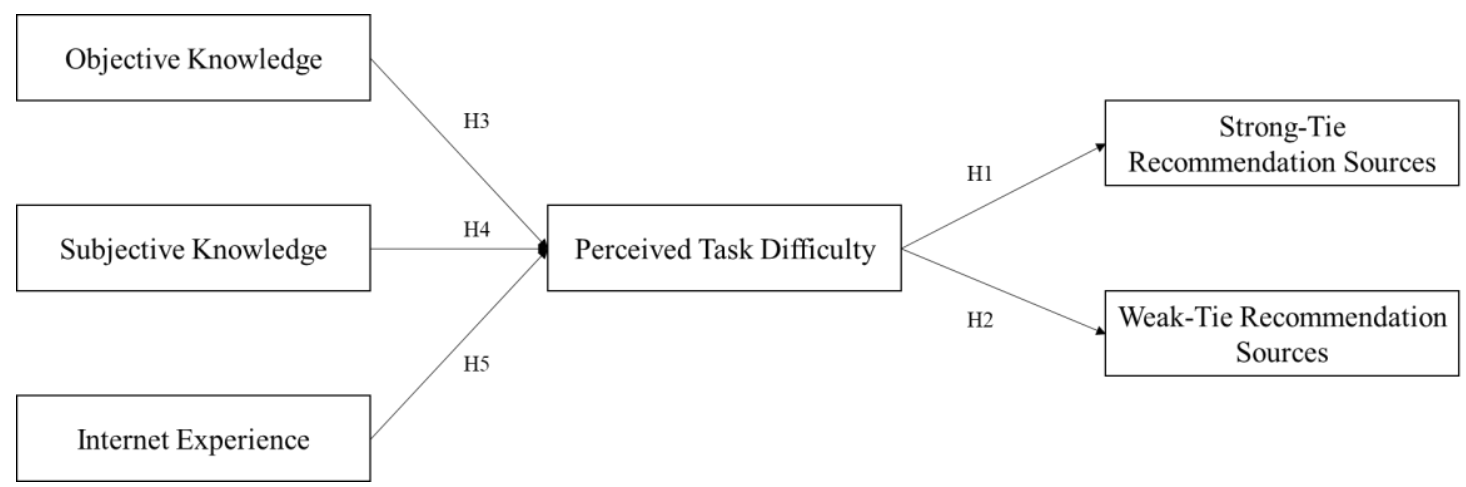

Figure 1 - Conceptual Framework 


\section{METHODOLOGY}

Since the study conducted is descriptive, a quantitative approach has been followed when conducting the research. In this research, the researcher has gathered information of different constructs via a rigorous literature review to understand consumer behavior and hypotheses have been built upon it. Due to time and resource limitations the researcher has selected only one sample of respondents out of the population and the data collection has been carried out only once. Hence it can be concluded that a single cross-sectional design has been adopted when designing the research (Malhotra \& Dash, 2011). Further, under survey approach a questionnaire was distributed among the respondents for data collection. Due to resource limitations, the questionnaire was identified as the best option available for data collection. Respondents were asked to limit the responses to the given alternatives in the questionnaire. A 5-point Likert Scale ranging from strongly disagree to strongly agree was used in the questionnaire for respondents to state their level of agreement to statements given in the questionnaire.

\section{Research Context}

The selection of the context for the test of this model was guided by the need to have a decision task that was both likely to involve recommendations and to be common enough that the typical consumer would see it as realistic and familiar. Due to the growing nature of travel websites, tour packages in the hospitality industry were chosen as the research context.

The research context was operationalized through the use of the scenario method. As the respondents were asked to assume they were in the given scenario and respond to the questionnaire, the situational effects associated are avoided. Further scenario provides the advantage of visualizing the decision situation more precisely and consistently. Based on the scenario given, the use of recommendation sources, perceived task difficulty, knowledge and prior internet experience have been measured. 


\section{Operationalization of Variables}

Table 1 - Operationalization of Variables

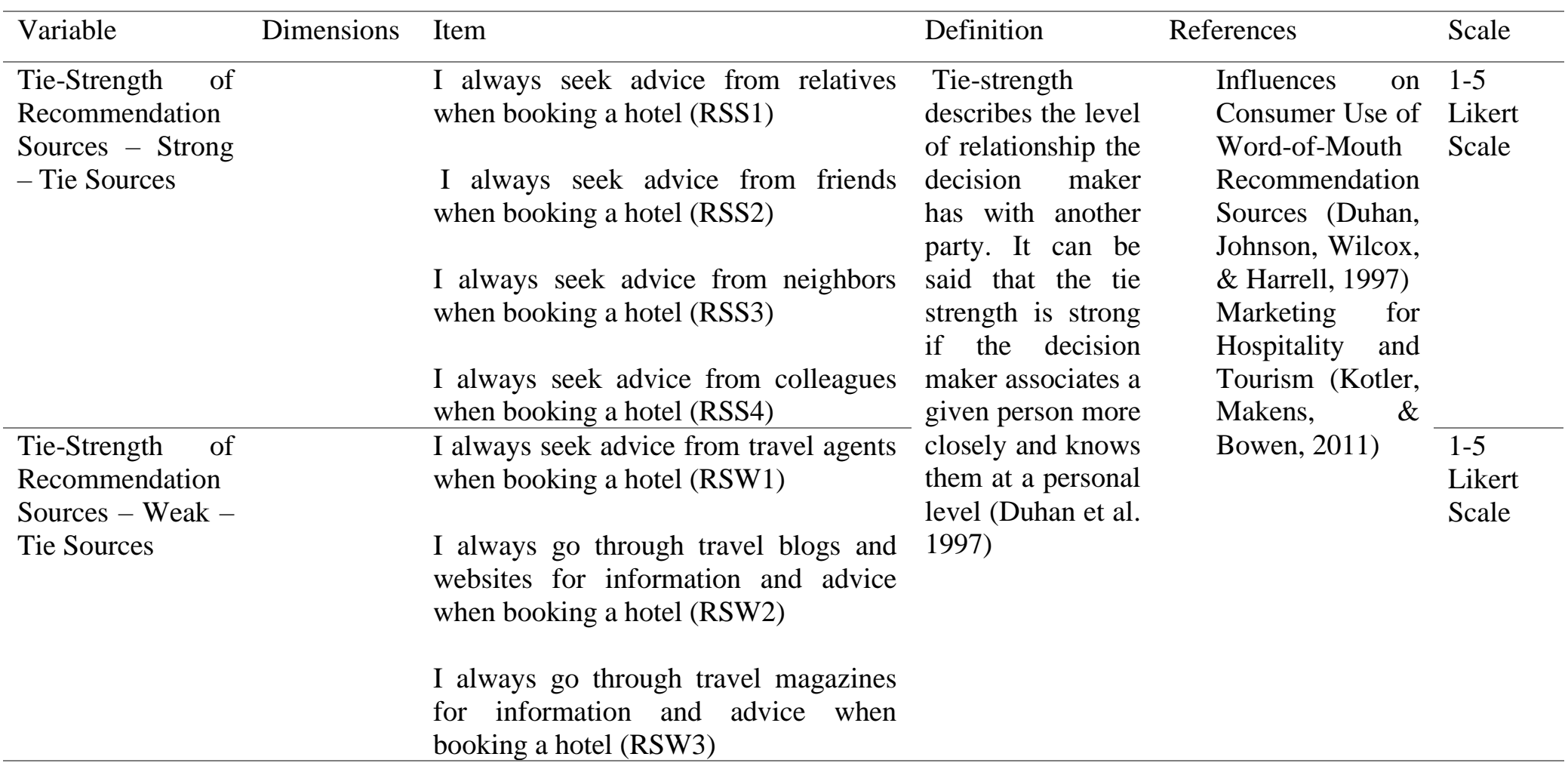




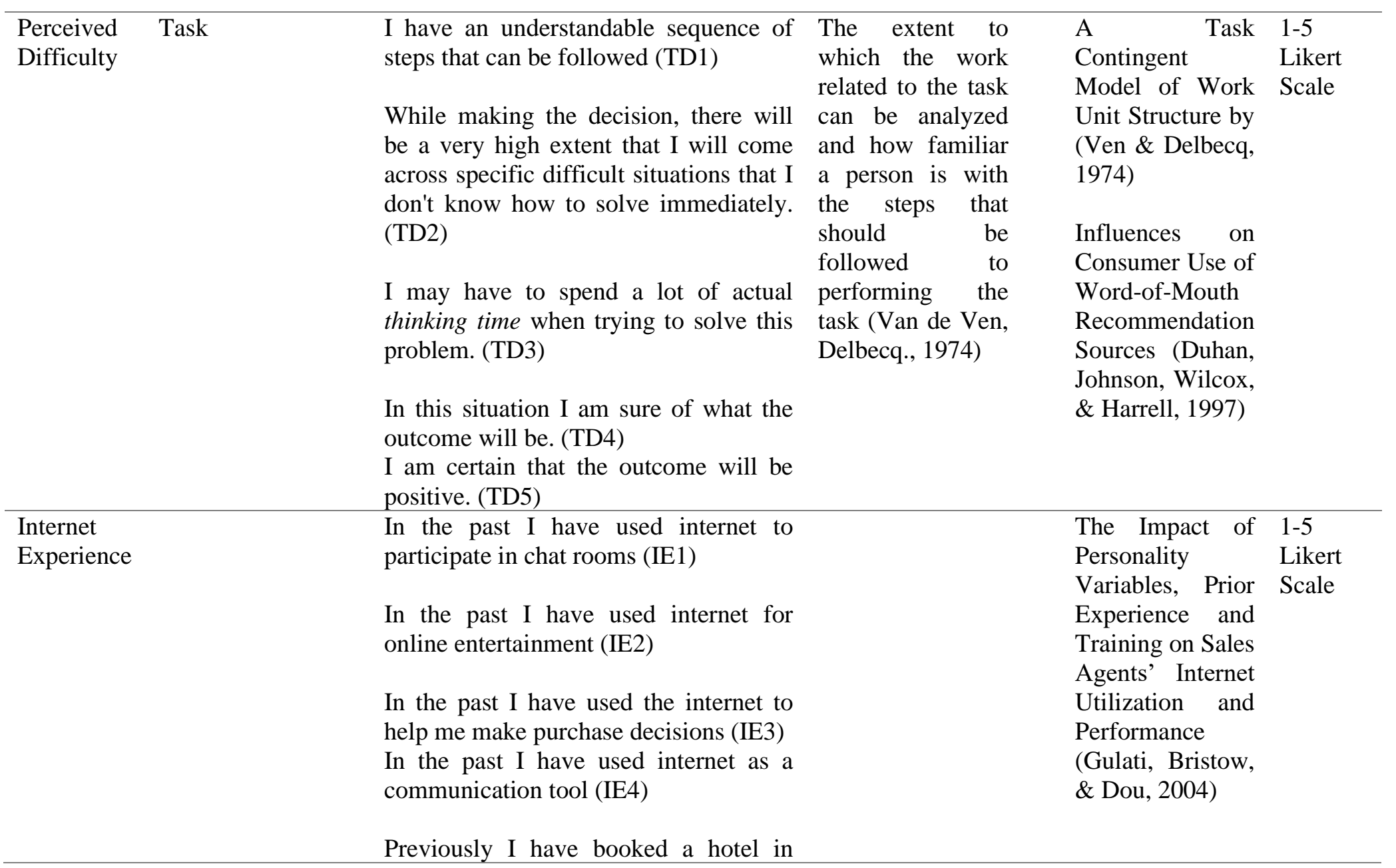


another country via internet. (IE5)

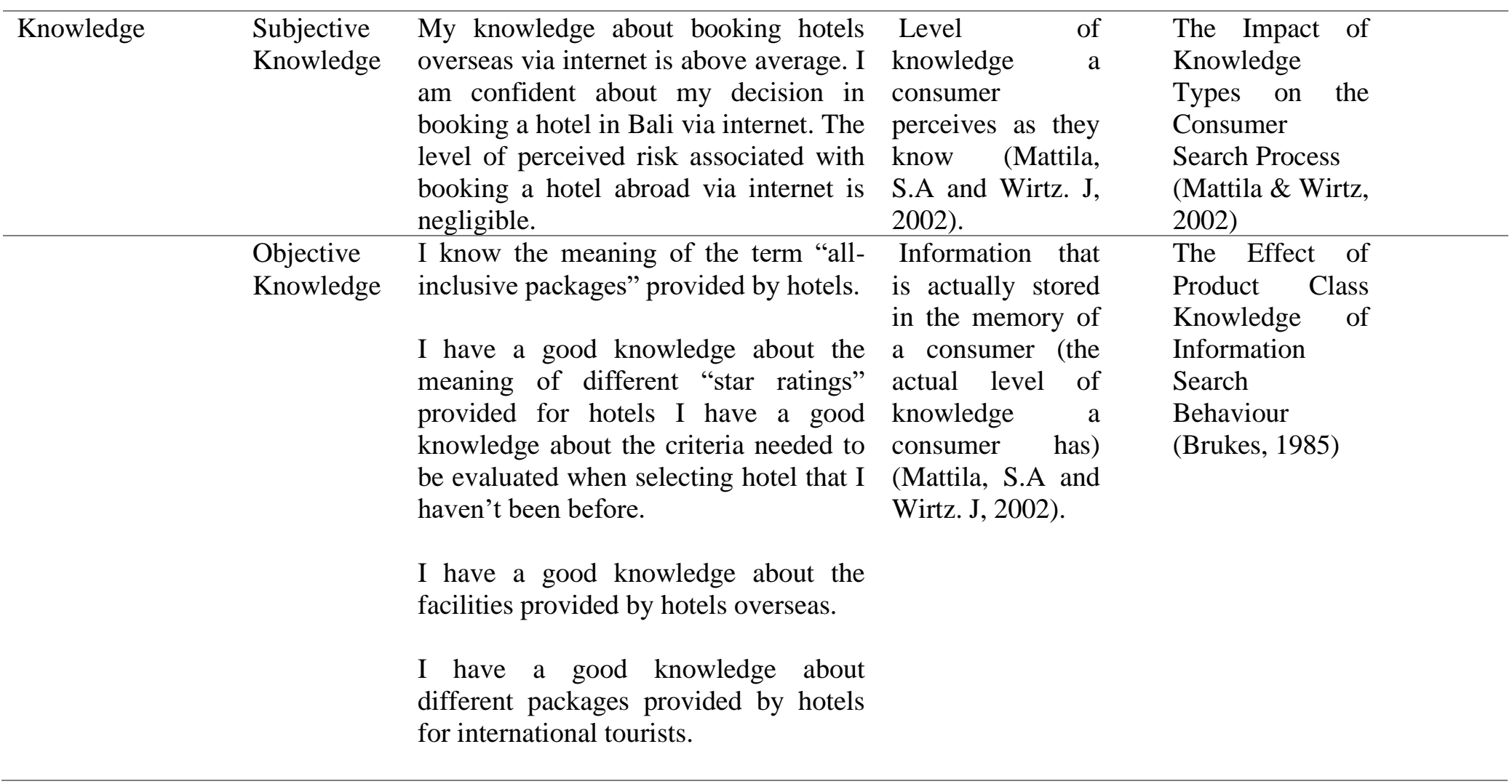




\section{Sampling Method}

Convenience sampling is used to select the sample. Since the research is based on online environment, a convenience sample has been used. Google forms were used to distribute the questionnaire among the respondents.

\section{Sample}

Table 2 - Analysis of the Sample

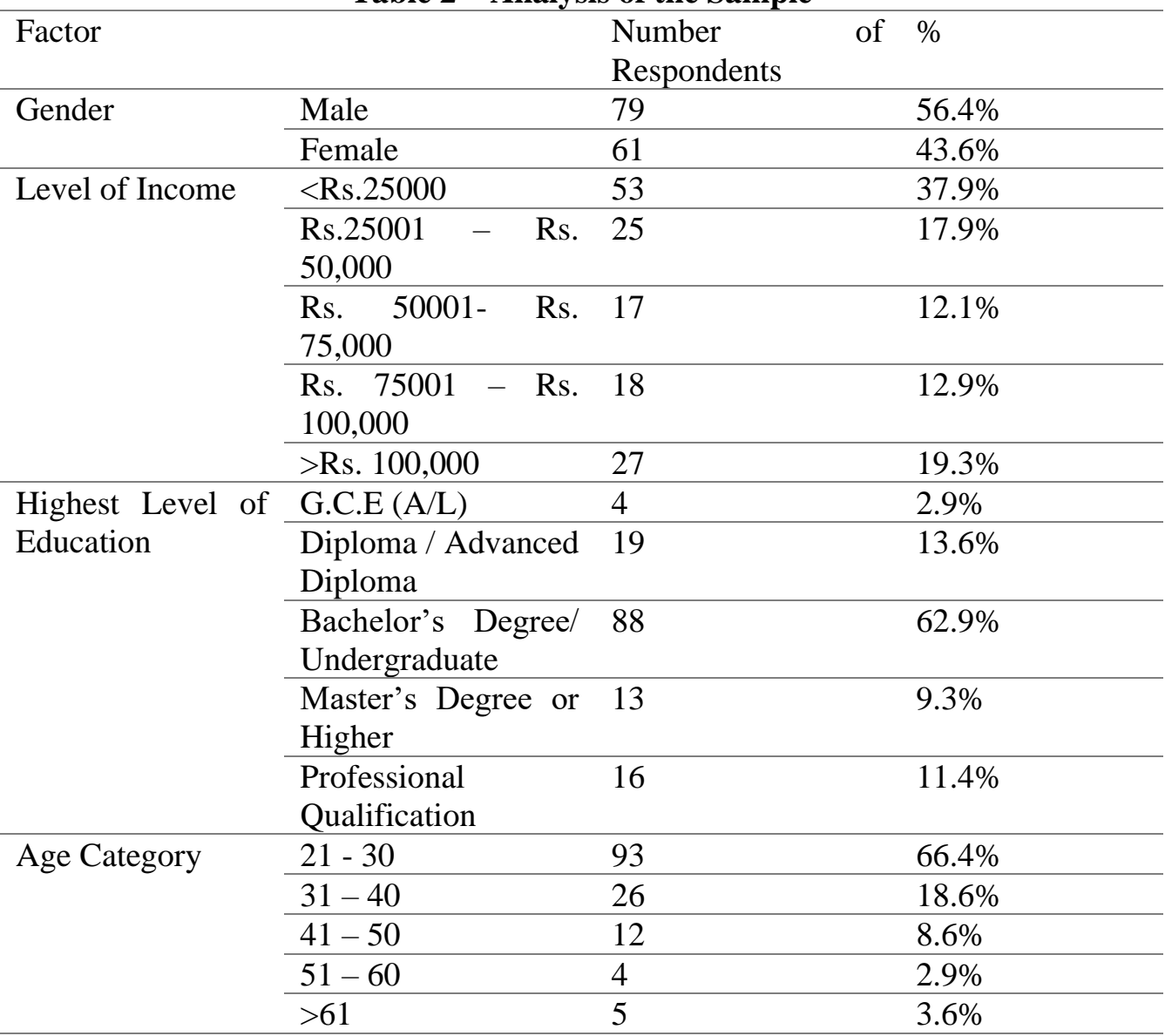

Source: Survey Data

Data gathered through the questionnaire were analyzed using Statistical Package for Social Sciences (SPSS) software. A correlation analysis was conducted, as the objectives and the hypotheses state about finding whether a relationship exists between variables Based on the results of the correlation analysis, hypotheses were accepted or rejected. 


\section{FINDINGS}

\section{Measuring Reliability and Validity}

Table 3- Results of Reliability and Validity Tests

\begin{tabular}{lllll}
\hline \multicolumn{1}{c}{ Variables } & $\begin{array}{c}\text { Chronbach's } \\
\text { Alpha }\end{array}$ & KMO & \multicolumn{1}{c}{$\begin{array}{c}\text { Bartlett's Test } \\
\text { p-value }\end{array}$} & AVE \\
\hline Strong ties & 0.769 & 0.646 & 0.000 & 0.5991 \\
\hline Weak ties & 0.652 & 0.5 & 0.000 & 0.7421 \\
\hline $\begin{array}{l}\text { Perceived Task } \\
\text { difficulty }\end{array}$ & 0.725 & 0.657 & 0.000 & 0.6499 \\
\hline $\begin{array}{l}\text { Internet experience } \\
\text { Consumer knowledge }\end{array}$ & 0.753 & 0.743 & 0.000 & 0.5671 \\
\hline
\end{tabular}

Source: Survey Data

Table 4 - Measuring Discriminant Validity

\begin{tabular}{|c|c|c|c|c|c|}
\hline & $\begin{array}{l}\text { Perceived } \\
\text { Task } \\
\text { Difficulty }\end{array}$ & Weak ties & $\begin{array}{l}\text { Internet } \\
\text { Experience }\end{array}$ & Knowledge & Strong Ties \\
\hline $\begin{array}{l}\text { Perceived } \\
\text { Difficulty }\end{array}$ & 0.8062 & 0.351 & -0.343 & -0.469 & 0.032 \\
\hline Weak ties & & 0.8615 & -0.519 & -0.475 & 0.201 \\
\hline Internet Experience & & & 0.7531 & 0.595 & -0.208 \\
\hline Knowledge & & & & 0.7486 & -0.115 \\
\hline Strong Ties & & & & & 0.7740 \\
\hline
\end{tabular}

Source: Survey Data

Internal consistency of a measure is indicative of homogeneity of the items in the measure that tap the construct (Uma Sekaran and Bougie, 2012). The widely used test to measure inter-item consistency is Chronbach's coefficient alpha. As mentioned by Prof. Neville Warnakulasooriya in his textbook Marketing Research: Measures of Marketing Construct, the generally agreed upon lower limits of 
Chronbach's Alpha is 0.7. As depicted in Table 3 the Chronbach's Alpha value for all variables are above 0.7 ; it can be said that the internal consistency has been met.

To measure validity of the questionnaire, Kaiser-Meyer-Olkin measure of sampling adequacy, Bartlett's Test of Sphericity and exploratory factor analysis were used. Kaiser (1974) recommends accepting KMO values greater than 0.5 as acceptable. Bartlett's measure tests the null hypothesis that the original correlation matrix is an identity matrix. In order for factor analysis to work a relationship should exist between variables. Therefore, the Bartlett's value should be significant (i.e., have a significance value less than 0.05) (Field, 2005). As shown in Table III for all variables KMO statistics are at 0.5 or above and Bartlette's value is significant as the p-value is less than 0.05 . Hence it can be said that the convergent validity criteria have been met.

As Uma Sekaran and Bougie (2012) explained, discriminant validity is established when, based on theory, two variables are predicted to be uncorrelated, and scores obtained by measuring them are indeed empirically found to be so. In order to establish discriminant validity to be met an AVE (Average Variance Extracted) analysis should be conducted. In an AVE analysis, it is tested to see if the square root of every AVE value belonging to each latent construct is much larger than any correlation among any pair of latent constructs. AVE measures the explained variance of the construct. The objective of the AVE analysis is to see whether the items or indicators of a given construct explain more variance than the items of other constructs (Zait \& Bertea, 2011). According to Fornell and Larcker (1981) the square root of the AVE of each construct should be higher than the correlation of the given construct with any of the other constructs. The value of AVE for each construct should be at least 0.50 (Fornell \& Larcker, 1981). As shown in Table III, AVE value for all variables is above 0.5 and as shown in Table IV, the square root of AVE value is larger than the correlation of the specific construct with any of the other constructs. Hence it can be said that the discriminant validity criteria have been met. As all three test criteria have been met it can be said that the questionnaire meets validity criteria.

\section{Correlation Analysis}

Based on the descriptive statistics, it was identified that all variables are approximately normally distributed; Pearson correlation analysis was conducted. Kolmogorov-Smirnov test is used as the sample size was above 50. 
Table 5: Summary of the Results of Correlation Analysis

\begin{tabular}{llll}
\hline \multicolumn{1}{c}{ Hypothesis } & \multicolumn{1}{c}{$\begin{array}{c}\text { Correlation } \\
\text { Coefficient }\end{array}$} & p-Value & Result \\
\hline Hypothesis 1 & 0.032 & 0.710 & H1 rejected \\
\hline Hypothesis 2 & 0.351 & 0.000 & H2 accepted \\
\hline Hypothesis 3 & -0.423 & 0.000 & H3 accepted \\
\hline Hypothesis 4 & -0.385 & 0.000 & H4 accepted \\
\hline Hypothesis 5 & -0.343 & 0.000 & H5 accepted \\
\hline
\end{tabular}

\section{DISCUSSIONS}

According to the analysis, $\mathrm{H} 1$ has been rejected. Though $\mathrm{H} 1$ shows a weak positive relationship between strong tie recommendation sources and perceived task difficulty, the relationship is not significant. In $\mathrm{H} 2$, there is a significant positive relationship between, weak tie recommendation sources and perceived task difficulty (significant at 0.01 level). Hence it can be said that consumers tend to seek information from all sources irrespective of the perceived level of difficulty of the task. Since the relationship between variables is significant $\mathrm{H} 2$ has been accepted. These findings challenge the research findings of Locander and Herman (1979), Brown and Reingen, (1987), Duhan, et al., (1997) where it says that consumers seek information from strong ties for tasks that are perceived as difficult. With the rise of travel blogs, reviews and comments consumers can easily get information even from unknown sources. Hence it can be said that even for difficult tasks, due to the convenience of obtaining information consumers tend to rely on weak ties.

Consumer knowledge can be divided into two parts as subjective knowledge and objective knowledge (Mattila and Wirtz, 2002). When the relationship between objective knowledge and perceived task difficulty was tested, it showed a negative relationship (-0.423) rejecting $\mathrm{H} 0$ in favour of $\mathrm{H} 3$ at a significant level of 5\%, which means as the actual level of knowledge of consumers increases, they perceive tasks with low difficulty. This is in line with the findings of Naderi, et al., (2018) where it says that prior knowledge supports in quick information retrieval for consumers.

The relationship between subjective knowledge (i.e., how much consumers perceive they know, Mattila and Wirtz, 2002), and perceived task difficulty has also become negative (-.385) rejecting Ho in favour of $\mathrm{H} 4$ (There is a negative relationship between subjective knowledge and perceived task difficulty). To further elaborate on this situation, even though consumers are not really knowledgeable about the situation or the task as long as they perceive their knowledge level is high, they tend to perceive tasks with low difficulty.

Test results of the relationship between perceived task difficulty and prior internet experience show a negative correlation (-.343) between the two variables. 
Therefore, at a 5\% level of significance Ho can be rejected in favour of $\mathrm{H} 5$ (there is a negative relationship between internet experience and perceived task difficulty). Hence it is possible to say that consumers who have experience in use of internet and who have engaged in electronic commerce are more comfortable in making purchase decisions via internet. These findings are in line with the findings of Wang \& Law (2020) and Naseri and Elliot (2011) which have proved that prior internet experience acts as an enabler and reduces the perceived task difficulty when making an online purchase.

\section{THEORETICAL CONTRIBUTIONS}

There is previous research done related to recommendation sources (Duhan, Johnson, Wilcox, \& Harrell, 1997), however this research discusses the role of recommendation sources when making an online purchase decision related to the tourism and hospitality industry. Further, 'prior internet experience' has been included in the model which was not captured in previous literature related to this context.

\section{PRACTICAL IMPLICATIONS}

Many consumers today shut out other media of communication, but by using word of mouth sources companies can reach out consumers that cannot be reached in other ways. As previous research has suggested consumer credibility in word-of-mouth communication, which is an earned medium, is higher than paid media of promotions. Hence based on the research findings it is important to treat word of mouth as an important tool in the promotional mix. Based on the identification of the choice of tie-strength based on the perceived task difficulties, hospitality companies can now identify which sources should be used as opinion leaders to influence the consumer decision making process. Generally perceived task difficulty in making a decision regarding a service or experience is higher than a physical good due to the low level of search qualities and high level of credence qualities in services/experiences than tangible goods. Therefore, in such situations such as tourism, word of communication is a better tool of the promotional mix. Organizations engaged in hospitality industry should identify advocates that can be used to promote as they are highly likely to recommend destinations, hotels to their friends and family. Further in the modern world, where social media is dominating, identifying influencers on social media and monetizing on them is a highly recommended strategy as they have a considerable follower base that sees and follows their updates on social media. Such strategy is recommended to increase the reach in promotional methods used.

The model proposed by this research enables organizations to measure the actual level of consumer knowledge (objective knowledge), perceived level of consumer knowledge (subjective knowledge). Companies can influence the consumer decision-making process by trying to make an impact on the level of consumer knowledge. Companies can make their consumers' decision-making process easier 
by providing information regarding their product or service, that means by making them knowledgeable (improving both the subjective knowledge and objective knowledge). Companies engaged in the tourism and hospitality industry can get the help of travel bloggers to provide knowledge to customers on practices, terminology, offers etc. As travel bloggers write or review based on their experience consumers tend to believe such information more. This may serve as a competitive advantage for the company since consumers have knowledge about the company's offering over competitor offering which will act as a factor to attract consumers to the company. As the official organization promoting tourism in Sri Lanka, Sri Lankan Tourism Promotion Bureau can implement such strategies to revamp tourism in the country and to attract more travelers.

The research has findings about the relationship between the perceived task difficulty and internet experience. Therefore, by studying the relationship between various factors managers can use various recommendation sources for various situations based on consumer knowledge, experience and perceived level of task difficulty. Also, these finding can be very important for companies which are engaged in B2C transactions via internet since internet is their primary mode of distribution. The relationship of internet experience to the source choice suggests that companies can use ties with less strength to influence experience consumers since their perceived level of task difficulty is less. Hence to influence such consumers who have prior internet experience companies can use social media and blogs heavily when promoting their products and services. Companies can also use cookies to track consumers experience and knowledge about using internet and build e-commerce platforms for online transactions based on the level of experience of target consumers (eg: If the target consumers have low level of internet experience the websites should be very simple and easy to understand. Also, in such situations it is beneficial to have offline modes of transactions too.)

\section{LIMITATIONS AND FUTURE RESEARCH DIRECTIONS}

As per this research, the only variable that has a direct influence on the selection of word-of-mouth recommendation source is the perceived task difficulty. However, in reality there can be other personal and contextual factors which impact the source selection. Also, even though the scenario appears realistic, respondents may not really engage themselves in the situation when answering the questions in the questionnaire. This research focuses only on one industry, hospitality industry. Therefore, research should be conducted based on other industries and depending on the industry situation choice of recommendation sources may vary.

\section{ACKNOWLEDGMENT}

A sincere gratitude goes to the reviewers of the Asian Journal of Marketing Management. 


\section{COMPETING INTERESTS}

The authors declared no competing interests.

\section{REFERENCES}

Ashan, K., \& Fernando, P. I. (2021). Electronic word mouth (e-WOM) as a wayforwarding strategy to uplift the profitability of boutique hotels in covid-19 era reference to southern coast, Sri Lanka. International Conference on Contemporary Management.

Brown, J., Broderick, A. J., \& Lee, N. (2007). Word of mouth communication within online communities: conceptualizing the online social network. Journal of Interactive Marketing, 21(3), 2-20.

Brukes, M. (1985). The Effect of Product Class Knowledge of Information Search Behaviour. Journal of Consumer Research, 12.

Choi, Y., Seo, Y., \& Yoon, S. (2017). E-WOM messaging on social media: social ties, temporal distance, and message concreteness. Internet Res., 27(3), 495-505.

Chu, S., \& Choi, S. M. (2011). Electronic Word-of-Mouth in Social Networking Sites: A Cross Cultural Study of the United States and China. Journal of Global Marketing, 263-281.

Chun, J. W., \& Lee, M. J. (2016). Increasing individuals' involvement and WOM intention on Social Networking Sites: Content matters. Computers in Human Behavior, 60, 223-232.

Dellarocas, C. (2003). The digitization of word of mouth: promise and challenges of online feedback mechanisms. Management Science, 49(10).

Duartea, P., Silva, S. C., \& Ferreira, M. B. (2018). How convenient is it? Delivering online shopping convenience to enhance customer satisfaction and encourage e-WOM. Journal of Retailing and Consumer Services, 44, 161-169.

Duhan, D. R., Johnson, S. D., Wilcox, J. B., \& Harrell, G. D. (1997). Influences on Consumer Use of Word-of-Mouth Recommendation Sources . Journal of the Academy of Marketing Science, 25(4), 283-295.

Ennew, C. T., Banerjee, A. K., \& Li, D. (2000). Managing Word of Mouth Communication: Empirical Evidence from India. International Journal of Bank Marketing, 75-83.

Field, A. (2005). “Factor Analysis with SPSS”, Research Methods II. 
Fornell, C., \& Larcker, D. F. (1981). Evaluating structural equation models with unobservable variables and measurement error. Journal of Marketing Research, 39-50.

Granovetter, M. (1973). The Strength of Weak Ties. American Journal of Sociology, 1360-1380.

Grewal, D., Roggeveen, A., \& Nordfält, J. (2017). The future of retailing. Journal of Retailing, 93(1), 1-6.

Gulati, R., Bristow, D. N., \& Dou, W. (2004). The Impact of Personality Variables, Prior Experience and Training on Sales Agents' Internet Utilization and Performance. Journal of Business-to-Business Marketing, 11(1-2).

Hennig-Thurau, T., Gwinner, K. P., Walsh, G., \& Gremler. (2004). Electronic word-of-mouth via consumeropinion platforms: what motivates consumers to articulate themselves on the internet? Journal of Interactive Marketing, 18(1), 38-52.

Hu, H.-h., Wang, L., Jiang, L., \& Yang, W. (2019). Strong ties versus weak ties in word-of-mouth marketing. BRQ Business Research Quarterly, 245-256.

Huang, C., Goo, J., Nam, K., \& Yoo, C. (2017). Smart tourism technologies in travel planning: the role of exploration and exploitation. Information Management, 757-770.

Huete-Alcocer, N. (2017). A Literature Review of Word of Mouth and Electronic Word of Mouth: Implications for Consumer Behavior. Frontiers in Psychology. doi:https://doi.org/10.3389/fpsyg.2017.01256

Huete-Alcocer, N. (2017). A Literature Review of Word of Mouth and Electronic Word of Mouth: Implications for Consumer Behavior. Frontiers in Psychology, 8, 1256.

International Trade Administration. (2021, Sep 28). Sri Lanka - Country Commercial Guide. Retrieved from International Trade Administration: https://www.trade.gov/country-commercial-guides/sri-lanka-travel-and-tourism.

Jesuthasan, S., Umakanth, N., \& Dineshkumar, S. (2020). The impact of negative e-WOM on consumer purchasing intention through virtual snowball sampling method: a special reference from Northern Province at Sri Lanka. International Journal in Management and Social Science, 8(7).

Kotler, P., Makens, J. C., \& Bowen, J. T. (2011). Marketing for Hospitality and Tourism (5th ed.). Pearson.

Li, W., Lee, A., \& Solmon, M. (2007). The role of perceptions of task difficulty in relation to self-perceptions of ability, intrinsic value, attainment value, and performance. European Physical Education Review, 301-318. 
Litvin, S. W., Goldsmith, R. E., \& Pan, B. (2008). Electronic word-of-mouth in hospitality and tourism management. Tourism Management, 29(3), 458-468.

Locander, B. W., \& Hermann, P. W. (1979). The Effect of Self-Confidence and Anxiety on Information Seeking in Consumer Risk Reduction. Journal of Marketing Research, 268-279.

Maity, M., Dass, M., \& Kumar, P. (2018). The impact of media richness on consumer information search and choice. Journal of Business Research, 87, 3645 .

Malhotra, N. K., \& Dash, S. (2011). Marketing Research - An Applied Orientation. India: Dorling Kindersley (India) Pvt Ltd.

Mattila, A., \& Wirtz, J. (2002). The impact of knowledge types on the consumer search process: An investigation in the context of credence services. International Journal of Service Industry Management, 13(3), 214-230.

Muniweera, C. D., Balawardhana, K. P., Rajapaksha, M. S., Chamara, M. A., \& Jayasuriya, N. A. (2020). The Importance of Factors Influencing on e-WOM Engagement towards Consumer Purchase Intention in Clothing Retailers, Sri Lanka. International Journal of Academic Research in Business and Social Sciences, 10(5), 349 - 360.

Naderi, I., K.Paswan, A., \& Guzman, F. (2018). Beyond the shadow of a doubt: The effect of consumer knowledge on restaurant evaluation. Journal of Retailing and Consumer Services, 45, 221-229.

Naseri, M. B., \& Elliot, G. (2011). Role of demographics, social connectedness and prior Internet experience in adoption of online shopping: Applications for direct marketing. Journal of Targeting, Measurement and Analysis for Marketing, 6.

Nawaz, S., Srivastava, N., Yu, J. H., Khan, A. A., Kennedy, G., Bailey, J., \& Baker, R. S. (2021). How Difficult is the Task for you? Modelling and Analysis of Students' Task Difficulty Sequences in a Simulation-Based POE Environment. International Journal of Artificial Intelligence in Education .

Nielsen. (2015). Global Trust in Advertising. Nielsen.

Park, J., Hyun, H., \& Thavisay, T. (2021). A study of antecedents and outcomes of social media WOM towards luxury brand purchase intention. Journal of Retailing and Consumer Services, 58.

Sekaran, U. B. (2012). Research Methods for Business - A Skill Building Approach. India: Wiley.

Seo, E. J., Park, J.-W., \& Choi, Y. J. (2020). The Effect of Social Media Usage Characteristics on e-WOM, Trust, and Brand Equity: Focusing on Users of Airline Social Media. Sustainability, 12(4). 
Silverman, G. (2001). The Secrets of Word-of-mouth Marketing: How to Trigger Exponential Sales Through Runaway Word of Mouth. New York: Amacom.

Su, P., Wang, L., \& Yan, J. (2018). How users' Internet experience affects the adoption of mobile payment: a mediation model. Technology Analysis \& Strategic Management, 30(2), 186-197.

Tran, G. A., \& Strutton, D. (2020). Comparing email and SNS users: Investigating e-servicescape, customer reviews, trust, loyalty and E-WOM. Journal of Retailing and Consumer Services, 53.

Ven, V. d., \& Delbecq. (1974). A Task Contingent Model of Work Unit Structure. Administrative Science Quarterly, 19(2).

Wang, J.-J., Wang, L.-Y., \& Wang, M.-M. (2018). Understanding the of eWOM social ties on purchase intentions: A moderated mediation investigation. Electronic Commerce Research and Applications, 28, 54-62.

Wang, L., \& Law, R. (2020). Relationship between Hotels' Website Quality and Consumers' Booking Intentions with Internet Experience as Moderator. Journal of China Tourism Research, 16, 585-605.

Warnakulasooriya, N. (n.d.). Marketing Research: Measures of Marketing Constructs.

Yusuf, A. S., Hussin, A. R., \& Busalim, A. H. (2018). Influence of e-WOM engagement on consumer purchase intention in social commerce. Journal of Services Marketing, 32(4), 493-504.

Zait, A., \& Bertea, P. E. (2011). Methods for testing discriminant validity. Management \& Marketing, 217-224. .

Zhang, M., Jansen, B., Sobel, K., \& Chowdury, A. (2009). Twitter Power, Tweets as Electronic Word-of-Mouth. Journal of American Society for Information Science and Technology. 